\title{
THE FESTIVAL AS CARNIVALESQUE: SOCIAL GOVERNANCE AND CONTROL AT PAMPLONA'S SAN FERMIN FIESTA
}

\author{
NEIL RAVENSCROFT* and XAVIER MATTEUCCI $\dagger$ \\ *University of Brighton, UK \\ $\dagger$ Canada
}

\begin{abstract}
Using empirical data from a questionnaire survey of residents and visitors attending the 1998 San Fermin fiesta in Pamplona, Spain, this article offers a critique of the contemporary construction of festivals as interpretive devices. Informed by the work of Bakhtin, this article makes the case that festivals should be understood as carnivalesque inversions of the everyday, deployed to maintain and reinforce social order and, thus, the discipline of bodies. This is achieved, it is argued, by creating "liminal zones" in which people can engage in "deviant" practices, safe in the knowledge that they are not transgressing the wider social structure they encounter in everyday life. It is suggested that the attraction of visitors is crucial, in providing a "cover" for this activity, as well as a conduit for the gradual legitimation of new and revised social values. The article concludes by arguing that this need for tourists (local and outsiders) is both recognized and embraced by residents and visitors alike, with neither fraction naive enough to believe that authenticity resides in representation, or even cultural (re)production.
\end{abstract}

Festivals Social relations Interpretation

Introduction: Festivals and the Reproduction of Social Relations

In this article, we offer a critique of the conventional understanding of festivals as texts about the culture of host communities (see Getz, 1991, 1994; Getz \& Cheyne, 1997; Hinch \& Delamere, 1993). While accepting that many festivals are associated with past events, the article echoes the work of Goldman and Papson (1994), in arguing that collec- tive memories are related less to their historical or social context, and more to the increasing abstraction and rerouting of cultural meanings. The focus of festivals is therefore not so much the events being celebrated as the intensity of the emotions evoked (MacCannell, 1992). Rather than sharing conventional concerns about the extent to which tourists can be inculcated into the culture of community festivals (Hinch \& Delamere, 1993), the article suggests that such festivals are essentially internal political devices, 
used for the purposes of grounding cultural meanings within current regulatory frameworks.

The article thus reflects Lefebvre's (1991) construction of the functionality of leisure spaces in reproducing, through the imposition of the rituals and gestures associated with festivals, particularized social relations. Lefebvre (1991) argues that these social relations operate to annihilate the sense of choice, freedom and self-determination suggested by leisure, instead offering: "an illusory sphere of freedom and choice which encourages a conformist and uncomplaining attitude in the masses" (Rojek, 1995, p. 98).

The article is based on a reading of Bakhtin's (1984) construct of the carnivalesque, in which festivals are viewed reflexively, as a "temporary liberation from prevailing truth and from the established order" (p. 10). Not only does this temporary liberation offer the possibility of excitement and entertainment, but also, as Hughes (1999) has pointed out with respect to the Hogmanay Street Party in Edinburgh, the potential to develop the new forms of regulation required to maintain social control. While making more than a passing reference to the gift relationship - that what is "given" can freely be taken away (Mauss, 1990)—Hughes (1999) argues that social regulation operates through "recuperat(ing) space with carnivalesque images of celebration and conviviality" (p. 132). As a result, following Hughes, the article argues that the festival is less a site for understanding the culture of host communities than it is a hegemonic device for promoting a particularized image of them: "With the intention of achieving an elision, they (city authorities) perform the standard marketing trick of associating an existing, and socially valorised, phenomenon with its representation in promotion. Hogmanay just is Edinburgh as the 24 Hour City just is Leeds, Cardiff, Manchester (or wherever)" (Hughes, 1999, p. 129).

Instead of viewing festivals as a means of promoting certain social, cultural, and economic community goals (Delamere, 1997), therefore, the article argues that festivals represent, in Foucault's (1975) terms, disciplinary heterotropia. While purporting to grant a level of freedom beyond that which is normally acceptable (Rojek, 1993), Shields (1992) argues that the heterotropia represents a liminal zone that offers neither genuine freedom nor genuine con- trol. Instead, it offers the possibility of a temporary lifting of the "moral curtain" followed by an embarrassed or guilty return to the moral code. While apparently offering an "elision of the everyday" (Shields, 1990), this "internalized" view of the festival places it firmly within the sphere of social regulation and control.

Rather than reflecting what Couldry (1998) sees as the elitist semiotic of the social and cultural authenticity of individual festivals, the article constructs authenticity as a function of the participant, not the event (Ravenscroft, 1999). Liminality thus represents less a site of closure or appropriation than it does an extension of the everyday, a celebration of "normality" viewed from, and constructed by, the elision of the carnivalesque. In this sense the carnival consumes - becomes - the everyday (MacCannell, 1992). Thus, rather than relating participant experiences to some abstract construct of cultural or historical authenticity (Goldman \& Papson, 1994; Hinch \& Delamere, 1993), the article makes the overt recognition that some participants may actively and knowingly seek the inauthentic as the basis of their experience.

As such, the article argues that rather than representing the possibility of external threats to local cultures (Jafari, Pizam, \& Przeclawski, 1990; Sheldon \& Var, 1984), festivals are part of an internal disciplinary structure that is, itself, vulnerable to external influence. For example, Getz and Cheyne (1997) discuss festivals becoming "known" for certain types of (unruly) behavior that are attractive to outsiders, while Hughes (1999) describes the growth of the Edinburgh Hogmanay Street Party as a major tourist attraction. As a result, we argue that festivals are fundamentally reflexive in nature, providing a legitimized break from the everyday routine while, at the same time, reenforcing the values underlying that routine. Rather than merely a license for particular types of behavior, therefore, we argue that the heterotropic construction of the festival (Foucault, 1977; Philips, 1998) ensures that, while there may be a temporary elision of the everyday, the cultural and moral codes remain intact and dominant (Shields, 1992).

The analytical context used in this article is the San Fermin fiesta (Los Sanfermines) in Pamplona, Spain. According to Stavrou (1999), this is the most well-known and best attended festival of its type, 
made particularly famous as the setting for Hemmingway's (1926) The Sun Also Rises. Although taking place in honor of the martyred Saint Fermin, patron saint of the religious societies of wineskin makers, wine merchants, and bakers (Ayuntamiento de Pamplona, 1999), the fiesta has become a major attraction for young people wishing to participate in a week-long street party and join the daily bullruns. In reflecting the work of Hughes (1999), the San Fermin fiesta just is Pamplona.

Although occurring for only 1 week per year, the San Fermin fiesta plays a dominant part in the cultural and economic life of the city. This is, however, less for its association with Saint Fermin than it is with its overt embrace of the contemporary carnivalesque. Having promoted Los Sanfermines as a popular fiesta, combining the religious and the profane, the local authority has made it clear that "anything out of the ordinary is welcomed and soon becomes part of the tradition, so long as it shows the respect due to others" (Gobierno de Navarre, 1998b). Indeed, the local authority stresses that, while respecting tradition, Los Sanfermines is essentially a living festival, taking place in the streets and through the people who inhabit them (Ayuntamiento de Pamplona, 1999).

We investigate this popular "making of tradition" through an analysis of the 1998 San Fermin fiesta. Based on a semistructured, multilingual questionnaire administered to both residents and visitors, the aim of the investigation was to explore the social and cultural impacts of the San Fermin fiesta. This was achieved primarily by examining and comparing residents' and tourists' experiences and understandings of the fiesta. This facilitated identification of the extent to which the residents and the tourists shared common interests in the fiesta, as well as locating the sources and impacts of differences in these experiences and understandings.

\section{Festivals as Carnivalesque}

Festivals, mostly related to religious rituals, have long been a part of social life in many societies, from the Dionysian celebrations of the ancient Greeks, to the carnivals of medieval Christendom and the contemporary Mardi Gras "parties" in Rio de Janeiro, New Orleans, and other cities (City of New Orleans, 1999; CNN, 1997; MacCannell,
1992; Mennell, 1989). What characterizes all of these celebrations are the rhythms and rituals surrounding them, the attention given to preparing for them, and the symbolism they hold for those involved (Bakhtin, 1984; City of New Orleans, 1999; Philips, 1998). As Bakhtin (1984) observes, during the Middle Ages, carnivals were the central leisure event in society, providing a temporary escape from the hierarchical and feudal structure that dominated life in the remainder of the year. Characterizing this inversion of the established order as carnivalesque, Bakhtin (1984) noted how the carnival effectively legitimated a utopian reaction against the order of "high" culture, thus establishing carnivals as sites of transgression, license, and excess (Rojek, 1993). This is, we argue, very much the case with the contemporary representation of the San Fermin fiesta (see Ayuntamiento de Pamplona, 1998, 1999).

While it has generally been recognized that such festivals and carnivals allow people to "let off steam," the work of Norbert Elias (1978) has only relatively recently provided an analytical framework within which to understand this process. In arguing that social survival is dependent upon individuals being able to exercise self-restraint, even when faced with strong feelings and emotions, Elias (1978) suggested that there was a need to provide and legitimate sites of release. In later work on the sociology of leisure, Elias and Dunning (1986) suggested that these sites provided appropriate spaces for the practice of mimetic activities, in which people are able to abandon the restraints on their emotions in relatively controlled and enjoyable surroundings. In some cases, festivals and carnivals thus reflect a joyous conclusion to an event, such as the harvest, while in others, such as the Mardi Gras, they are effectively the "feast before the fast" leading up to Easter (City of New Orleans, 1999; CNN, 1997). In both cases, festivals and carnivals appear to break the cycle of social containment (Mennell, 1989).

Rather than representing a site of celebratory freedom, therefore, the carnival is more appropriately viewed as a site for the discipline of bodies at play (Philips, 1998). In reflecting the production orientation of work, through the preparation of costumes, food, and the site, the carnival legitimates the wider social structure while also allowing the possibility of some temporary release from it. In this sense the 
festival or carnival is very much a transitional project (Ravenscroft, 1999), providing a created environment in which people can reject social order from within a structure that is familiar to them. As Rojek (1995) argues, this rejection is thus a socially constructed and controlled illusion: "And so the attempt to escape perishes because it depends upon the very conventions which make everyday life possible" (p. 88).

While being part of an internal social regulatory mechanism, the carnivalesque is also becoming increasingly commodified, principally through the attraction of outsiders - tourists - to gaze on and participate in the spectacle (Philips, 1998). Indeed, many large-scale carnivals are now major international tourist attractions, enjoyed for their atmosphere and spectacle rather than their historic associations (Ayuntamiento de Pamplona, 1999; CNN, 1997). Participation in the festival or carnival is thus no longer predominantly an act of production, but rather also one of consumption, provoking Shields (1991) to comment that "even in its most carnivalesque forms, social exchange is marked by economic exchange" (p. 9).

Rather than offering a socially regulated site in which to break the cycle of social containment, therefore, Philips (1998) argues that the festival or carnival can become a primary expression of the disempowerment of local people. Rather than being their chance to engage in mimetic leisure practices, local people may increasingly be forced into the role of service provider, either directly through the organization of the event, or in providing a cultural backdrop and linkage to the past. Much is made, for example, of the traditional San Fermin costumes worn by local people during the fiesta in Pamplona (Ayuntamiento de Pamplona, 1999). Such disempowerment can result in a number of impacts, including increasing economic dependency (Belisle \& Hoy, 1980), increasing cultural isolation and sensitivity (Sheldon \& Var, 1984), and declining social structure and cohesiveness (Jafari et al., 1990; Nogués Pedregal, 1996). While other authors (Hinch \& Delamere, 1993, for example) argue that these impacts can be minimized by controlling the number of tourists at the event, it is the very presence of outsiders that shifts the construct of the festival from celebration to spectacle, from production to consumption. All these aspects of the carnivalesque are illustrated in the following study of the San Fermin fiesta in Pamplona.

Pamplona: Social Order and the San Fermin Fiesta

Situated between the Pyrenees and the Iberian Mountains, the Spanish province of Navarre covers an area of $10,391 \mathrm{~km}^{2}$ and had, in 1995 , a population of 519,277, over one third of whom lived in Pamplona. The history of Pamplona can be traced back to the Roman General Pompey in 74 A.D. The local people are proud of their history, with folklore being very much alive in Navarre (Gobierno de Navarre, 1997). Tourism is now an important source of revenue in Navarre, accounting for $4 \%$ of GNP (Gobierno de Navarre, 1998a).

The Catholic Church remains a dominant force in the social order of Navarre, with mass being celebrated regularly by significant sections of the population. Although there are no official data, it is thought that a large number (as many as half) of Pamplona's adult residents are members of Opus Dai, a movement described by Bompard (2001) as "the most important and determined militant organisation in the Roman church." The underlying rationale of Opus Dai is to encourage lay Catholics to live a "religious and saintly life." It is thought that members of Opus Dai are well represented in local politics, own many of the most important businesses in Pamplona, as well as considerable land and property holdings. Opus Dai is also influential in the Universidad de Navarre, a noted center of doctrine and ideological development.

While not all people may belong to Opus Dai, or even the Catholic Church, the religious culture and tradition is deeply embedded in the social order of Pamplona. This is particularly the case within the family, where patriarchy remains dominant and the discussion of issues such as sexual permissiveness and drug abuse is often repressed. Although there is evidence that younger people are more open to external influences than their parents, in everyday life they are granted little freedom to express their ideas and values. Rather, strict parental control is maintained, with most young people continuing to live at home until (and often after) they are married. This has undoubtedly led to much covert behavior and breaches of the social order (it is claimed, for example, that Navarre has the highest per capita rate 
of marijuana smoking in Spain). Interestingly, the same codes do not operate with respect to the consumption of alcohol, with drinking being an integral element of family life, particularly in relation to shared meals.

Secular regulation of the social order also occurs outside the family unit, principally through widespread membership of Penas (social organizations). These associations are important institutions in the maintenance of traditions and social fabric. They hold parades, parties, dances, and other celebrations throughout the year, and are important in the social organization of the fiestas. Although the Pena festivities during the San Fermin fiesta are open to everyone, their preparation, involving traditional costumes, food, and drink, provides a focus for cultural (re)production. The activities of the Penas thus provide an element of regulation within the social sphere, in drawing local people into common activities and shared values.

Despite the numerous autumn, winter, and spring religious festivals, it is only the San Fermin fiesta that has an international profile. Taking place in early July, the San Fermin fiesta attracts nearly 300,000 visitors to Pamplona, of whom $60 \%$ come from outside Spain. The fiesta is also a defining moment in the domestic social calendar, with many residents of Pamplona involved in planning, running, and participating in it. The festival lasts for just over 1 week, commencing with the Chupinazo at midday on July 6th and ending with the Pobre de mi at midnight on July 14th.

The religious origins of the festival are still reflected in events such as the Procession on the morning of the $7 \mathrm{th}$, although new elements have been added, such as the Chupinazo itself (an inaugurating rocket to open the fiesta), or the cultural program (Ayuntamiento de Pamplona, 1999; Azpilicueta \& Domench, 1994). In addition to these events, there are bullfights, a dance festival, a rural sports festival, concerts, fireworks, a funfair, and daily parades, all encapsulated within the 7-day "party" (Ayuntamiento de Pamplona, 1998). However, it is the encierro, or bull-run, that is the best known part of the festival. It consists of men (and women dressed as men, because women are forbidden from participating) running in front of the bulls that are to take part in the afternoon's bull fight, or corrida:
Formerly, when the herdsmen brought their bulls across country from their pastures to be fought in the bull ring, they used to spend the night near the city and on the day of the bull fight, at dawn, they would be run through the town accompanied by oxen or tame bulls, and people who on horseback or running alongside, helped to drive them into the stalls with shouts and sticks. (Azpilicueta and Domench, 1994, pp. 25-26)

This "tradition" is now reenacted on each morning of the fiesta, with the bulls running from their overnight corral at the Santo Domingo along a barricaded route through the streets to the bullring at the Plaza de Toros. The route of the encierro is recorded on a number of official and unofficial Web sites (Ayuntamiento de Pamplona, 1999; Stavrou, 1999; The Scarlet Macaw, 1999). Rather than being accompanied by their herders, the bulls now form part of a spectacle in which they "chase" a large group of runners, who try to beat them to the Plaza de Toros. The popularity of this event is such that it has become a central part of the San Fermin experience (Stavrou, 1999), for both locals and visitors alike. Indeed, many visitors return year after year to participate, to the extent that it has taken on an identity that is increasingly separated from the fiesta itself, characterized by specialized tours to celebrate the "Millennium run," for example (The Scarlet Macaw, 1999).

\section{Collection of Data on Resident and Visitor Attitudes to the Fiesta}

A triangulated data collection methodology was used, comprising a face-to-face questionnaire survey, in-depth interviews, and participant observation. Three questions were developed for the research:

- How does the fiesta function as a system of social regulation?

- What are the roles of commodification and the production of spectacle in this system of social regulation?

- How do residents and tourists internalize the contradictions of commodification and regulation?

Two separate questionnaires were designed, one for the residents and one for the tourists. The resident questionnaire was informed by King, Pizam, 
and Milman (1993), in their study of the social impacts of tourism. The visitor questionnaire followed a similar format, but with questions relating to visitor's knowledge and experience of, and attitudes towards, the fiesta. In both cases, respondents were asked to weight their answers according to a 5-point Likert-type scale.

The questionnaire survey was carried out in the old town of Pamplona, to gather information on residents' and visitors' perceptions of the San Fermin fiesta. In addition, information was also collected in the questionnaires on residents' attitudes towards, and perceptions of the sociocultural impacts of, the tourists who came to the fiesta. Some 118 fully completed questionnaires were collected, comprising 68 resident questionnaires and 50 tourist questionnaires.

The questionnaire responses were achieved by quota sampling people in the streets, on a "next available person" basis. This meant that as soon as one interview was completed, the interviewer approached the next available person on the street to secure the next interview. If this person did not agree to be interviewed, the next available person was approached, and so on. All data were processed using Excel for Windows. Unweighted arithmetic means were derived for each question, with comparisons made using an independent samples $t$-test (the assumption being that the samples came from a population with a normal distribution).

The analysis of the questionnaire responses was supported by participant observation and official and unofficial descriptions of the fiesta, taken largely from documents posted on the World Wide Web. The participant observation took place over a 2-week period, commencing a few days prior to the fiesta. It comprised the researcher observing behavior during both formal events (including the bull running, religious procession, and parades) and informal activities (notably the street party). Particular behaviors and happenings were recorded, for subsequent categorization into broad behavioral typologies. These observations were used to inform the questionnaire findings, particularly in attempting to verify the claims being made. Because the participant observation was used in this way, as a support to the questionnaire, it is not analyzed separately or specifically in this article.

\section{Study Findings: Evidence of Inversions of the Social Order}

\section{General Profile of Respondents}

Most of the resident respondents were 18 to 40 years old and were divided equally between males and females. Most (78\%) were born in Navarre, with the bulk of the remainder having lived there for most of their lives. The majority of the resident respondents were single $(68 \%)$ and were employed either full- or part-time (50\% employed full-time, $20 \%$ employed part-time). Of those in employment, nearly half (42\%) worked in the "tourist industry." However, largely because of the fiesta, many people working in the old town of Pamplona associated their business activities with tourism, even if they sold clothes or groceries. In addition to those employed in tourism, an additional $13 \%$ of the respondents had one or more immediate family members employed in this sector.

According to the overall data for the city and region (Gobierno de Navarre, 1998a), the resident respondents are not representative of the entire population, being younger, more economically active, and more fully employed in tourism than the overall population. However, this was to be expected when undertaking the survey in the old town at the time of the fiesta.

While it is officially estimated that $60 \%$ of the tourists to the San Fermin fiesta are from outside Spain (Gobierno de Navarre, 1997), the respondents to the survey were almost exclusively foreign (98\%). It was not possible to establish why this should have been the case, although the nationality of the interviewer (French, but with fluent Spanish) may have contributed, particularly to some Spanish tourists classifying themselves as locals. As a result, the visitor survey very much reflects the opinions, views, and experiences of foreign tourists.

In common with the residents, the majority (66\%) of the visitors surveyed were young (less than 30 years of age), although more of them were male than in the resident population. Only $8 \%$ of the visitors surveyed were older than 51 years of age. Again in common with the residents, the majority of the visitor respondents were single (70\%). More than half the visitor respondents $(62 \%)$ were on their first visit to Pamplona for the Sanfermines. This is consistent with the official data collected at the 1997 fiesta 
(Gobierno de Navarre, 1997). The visitor respondent sample was heavily influenced by French and American tourists, who comprised $30 \%$ and $24 \%$ of the sample, respectively. The presence of large numbers of French visitors was to be expected, given Pamplona's proximity to the French border. However, the large number of Americans (compared to the 1997 survey) is harder to explain, although the interviewer perceived that they had a greater propensity to agree to be interviewed than some other tourists.

The primary declared purpose of the respondents' visits to Pamplona was to see the festival (48\%), while a further $30 \%$ admitted coming to drink and have fun. Although they stayed in Pamplona for an average of 5 days, about half of the visitors were not accommodated at all, but "slept rough." Of the others, approximately one third stayed at hotels and guesthouses, while the remainder camped. These findings are in line with the official data for 1997 (Gobierno de Navarre, 1997), and illustrate the marginal economic impact of this aspect of the fiesta, with visitor respondents spending an average of less than US\$50 each on accommodation during their stay in Pamplona.

\section{The System of Social Regulation}

Central to the system of social regulation is the understanding by residents that the fiesta happens in a predetermined "envelope" of time and ritual each year. This envelope thus has both a temporal definition (from July 6th to 14th each year) and a ritualistic one (from the Chupinazo - the opening ceremony - to the Pobre de mi - the closing ceremony). During this time, the citizens feel "encouraged" to have a good time and to celebrate their religion and their cultural identity (Table 1). This is the intended essence of the Sanfermines, with the local government encouraging the citizens to take to the streets to enjoy themselves in the company of others.

While superficially congruent with MacCannell's (1992) reading of such events, with people moving from everyday atomization to the community of the fiesta, the actuality is quite the reverse. With its foundation in the Church and family, everyday social order in Pamplona is characterized by community and its associated surveillance. During the fiesta, local people have the ability to "lose" themselves in
Table 1

Meaning of the Festival to the Residents

\begin{tabular}{lcc}
\hline Variables & Frequency & Percentage \\
\hline 1. The celebration of a cultural identity & 34 & 50.0 \\
2. An opportunity to drink and & 18 & 26.5 \\
$\quad$ have some fun & 1 & \\
3. An opportunity to meet foreigners & 4 & 1.5 \\
4. A religious celebration & 11 & 5.8 \\
5. Other & 68 & 16.2 \\
Total & & 100.0 \\
\hline
\end{tabular}

the crowds, to effectively become tourists in their own city. In this way they can avoid, temporarily at least, the everyday regulatory mechanisms. They also blur the distinction between resident and visitor. As such, the principal inversion of the fiesta is the replacement of one community - the family and church - with another-the participants in the party that is the fiesta. This facilitates-in the party at least-a further inversion of the social order, in replacing the dominant chauvinism of the family unit and religious order with a more egalitarian form of social engagement.

However, some "traditions" are maintained, such as prohibiting women from participating in the encierro. The project here is very much to maintain some (arguably the key) elements of chauvinistic social order. However, women do participate, but dressed as men. This offers in effect a "double inversion" that seeks to destabilize the apparent egalitarianism of the carnival, by implying that such equality can only be achieved by women subscribing to male dominance. This is epitomized by Stavrou's (1999) characterization of the women as "rebellious conformists": rebellious in choosing to participate, but conformist in doing so disguised as men.

While apparently encouraging the inversions (or at least not preventing them), officials have sought to provide both moral and physical boundaries to the activities. The moral boundaries involve linking individual enjoyment with the maintenance of respect for others (Ayuntamiento de Pamplona, 1999). This is reinforced by the policing regime developed for the fiesta (Azpilicueta \& Domench, 1994). The physical boundaries are those controlling the crowds at the main events, especially in keeping the bulls away from the spectators at the daily encierro. As 
Azpilicueta and Domench (1994) comment, these physical boundaries also now require enforcement by the police, in ensuring that the events happen in the ways intended by the local authority. In the cases of both the moral and physical boundaries, social regulation is constructed as a "natural" part of the fiesta, there to ensure that everyone is able to have a "good time."

While recognizing that the fiesta is essentially about having fun, much emphasis is placed on its religious dimensions and origins. This is respected by the residents, the majority of whom associate the fiesta with their religion, culture, and heritage, although less than half of them claim to understand or to be able to explain the origins of the fiesta.

While being a festival for local people, it is not coincidental that tourists are actively welcomed. Unlike many other festivals, however, it is apparent that the welcome is less for the economic benefits that tourism brings than it is for the essential part that tourists play in the social regulation of the host community. This is evidenced by the relative apathy towards the tourists by those working in Pamplona's tourist industry (Table 2).

Rather, the tourists attending the Sanfermines are part of what the local authority characterizes as Pamplona's "tradition" of welcoming strangers (Ayuntamiento de Pamplona, 1999). This supposedly reflects the origins of the fiesta, when outsiders came to the town with their bulls. It also legitimates a form of liminality, in encouraging external influence and seeking to incorporate this within the social order of the town, at least for the duration of the fiesta. This is supported by many of the residents, the majority of whom see the tourists as different from themselves. They thus appear to welcome the tourists to the town, superficially as a sign of Pamplona's openness to difference (Table 3).

Yet, while some locals welcome the tourists, others characterize them as rude, disrespectful, aggressive, destructive, and dirty. This is encapsulated by the view that the tourists do things at the fiesta that they would not do at home, while having little understanding of, or interest in, the cultural and religious origins of the fiesta. Yet, of course, it is not just the outsiders that engage in this behavior, but locals as well. For them, the presence of the tourists effectively hides, or at least masks, their own inversion of the social order.

This is the essential distinction that locals make between themselves and tourists: they all do things at the fiesta that they would not normally do, but the residents are able to do so subversively, by assuming a role assigned by others to the tourists. The regulatory frame created by the local people thus uses the tourists as, effectively, the spectacle in a oneway mirror on liminal activities-illustrating that conventional conduct can be inverted during the fiesta. At the end of the fiesta, however, the tourists depart (the outsiders leaving and the locals returning to their home lives) and Pamplona "reverts" to its previous self.

This is very much how the residents construct the impact of the tourists: while feeling that the fiesta has changed over the years, the dominant construction is that the changes reflect social develop-

Table 2

Perceptual Differences Between Those Employed and Not Employed in the Tourism Industry

\begin{tabular}{lrrr}
\hline & & \multicolumn{2}{c}{ Means } \\
\cline { 2 - 4 } Attitudinal Statements & $\begin{array}{r}\text { Employed } \\
\text { in Tourism }\end{array}$ & $\begin{array}{c}\text { Not Employed } \\
\text { in Tourism }\end{array}$ & $\begin{array}{l}t \text {-Test } \\
\text { Value }\end{array}$ \\
\hline How do you feel about the presence of tourists in the community during the fiestas & 3.350 & 3.949 & -2.07 \\
The tourists visiting Pamplona are similar to the residents & 1.850 & 1.821 & 0.11 \\
The domestic tourists visiting Pamplona are similar to the foreign tourists & 2.350 & 2.256 & 0.30 \\
The tourists are friendly & 3.450 & 3.436 & 0.05 \\
The tourists treat the town well & 2.400 & 2.231 & 0.60 \\
The town would be a better place if the tourists did not come & 2.800 & 2.718 & 0.43 \\
The tourists are interested in Navarre's heritage & 2.400 & 2.308 & 0.31 \\
The tourists understand the cultural meaning of the fiestas & 2.000 & 1.897 & 0.46 \\
\hline
\end{tabular}

Scale: 1 = strongly disagree, $2=$ disagree, $3=$ neutral, $4=$ agree, $5=$ strongly agree. 
Table 3

Overall Residents' Attitudes Towards the Tourists in Pamplona During the Fiesta

\begin{tabular}{llr}
\hline Attitudinal Statements & Mean & SD \\
\hline The tourists are friendly & 3.485 & 0.915 \\
The tourists treat the town well & 2.235 & 1.002 \\
The town would be a better place if the tourists did not come & 2.794 & 0.796 \\
The tourists are interested in Navarre's heritage & 2.294 & 0.986 \\
The tourists understand the cultural meaning of the fiestas & 1.941 & 0.838 \\
\hline
\end{tabular}

Scale: 1 = strongly disagree, 2 = disagree, $3=$ neutral, $4=$ agree, $5=$ strongly agree.

ment in Pamplona, with the tourists being no more than an ephemeral "side-show." Yet there is recognition that, while the changes may be part of a wider shift in local culture and values, the tourists bring with them - and leave behind-influences from the world outside Pamplona. For example, the older residents view sexual permissiveness among the young as a negative, but temporary, part of the fiesta. The younger residents reject this construct in favor of a view that their activity during the fiesta is little different to other times, thus indicating that the sexual attitudes and practices of young people in Pamplona are no different than elsewhere. In this and other ways the residents of Pamplona use the fiesta to promote their own social projects, whether related to confirming or rejecting particular values and behaviors.

The Role of Commodification and the Production of Spectacle in the System of Social Regulation

In encouraging tourists to participate in the fiesta, there is little doubt that the local authority has contributed to its commodification. In particular, the Web site and official publications make sure that Pamplona is associated with the bull running and the partying, that in Hughes (1999) terms, Pamplona just is the encierro and associated events. This is certainly recognized by some of the residents, with $54 \%$ of the questionnaire respondents believing that the fiesta had been overtly commercialized for the benefit of the tourists.

This is reflected in the reasons given by the tourists for coming to the fiesta. As Table 4 illustrates, the nightlife was the aspect of the fiesta that most aroused interest among the visitors (particularly young males), followed by meeting local people and the running of the bulls. This echoes Getz and Cheyne's (1997) assertion that places and events become "known" for particular phenomena-in Pamplona's case the partying, the adrenaline-rush of the bull-running and the presence of "drunk Spanish (to) lend some authenticity" (Stavrou, 1999, p. 2).

However, it is not the authenticity of the "drunk Spaniard" that draws tourists, but rather the commodification of the "drunk Spaniard" as a sign that the fiesta retains authenticity for local people. Thus, tourists value meeting local people while admitting that the cultural and social heritage of the fiesta is of little concern to them, and that they would not be worried if it were staged for their benefit. This corresponds with MacCannell's (1992, p. 233)

Table 4

Degree of Visitors' Interest in Various Aspects of the Fiesta

\begin{tabular}{lcc}
\hline Aspects & Mean & SD \\
\hline Night life & 4.520 & 0.728 \\
Local people & 4.120 & 0.909 \\
Running of the bulls & 4.040 & 1.248 \\
Spanish culture & 3.900 & 1.044 \\
Climate & 3.640 & 1.015 \\
Local architecture & 3.640 & 1.015 \\
Local history & 3.580 & 1.146 \\
Procession & 3.260 & 1.002 \\
\hline
\end{tabular}

Scale: $1=$ not interested at all, $2=$ not really interested, $3=$ neutral, $4=$ interested, $5=$ strongly interested. 
construction of the promiscuous tourist, who can enjoy a ceremony or ritual with no knowledge of, or interest in, its cultural significance.

Conversely, the "drunk Spaniard" is legitimated by the presence of "drunk tourists," to the extent at least that the fiesta has a significance beyond the boundaries of Pamplona. Nowhere is this better illustrated than in the commercial transformation of the encierro into a major televised spectacle, "successful" to the point that it now suffers from overcrowding and course "invasions":

\begin{abstract}
Nowadays there are too many runners and, in spite of various disuasory (sic) and restrictive measures, the bulls make the run completely surroundedsometimes blocked-by the young people who invade the course before ... the opening of the enclosures and the setting free of the bulls. ... In order to avoid overcrowding, where ever possible the run is sectioned off by the local police, who withdraw moments before the bulls arrive. (Azpilicueta and Domench, 1994, pp. 26-27)
\end{abstract}

While there are no official data on who runs in the encierro, it is patently clear that it is no longer just the locals (legend has it that the runners originally belonged to the Guild of Butchers). Equally, it is not only a tourist attraction, with many young local people running alongside the tourists. As such, each group legitimates the other in the "deviance" of the encierro. Without the tourists it is doubtful that the encierro would attract the live and television audiences, being susceptible instead to becoming a divisive contest of local bravura. Without the locals, the encierro would become, for the tourists, pure commodification. As such, the spectacle and partial commodification of the encierro is used to underpin the continuing legitimacy of the entire fiesta.

Allied to the spectacle of the encierro is the importance, to the tourists, of the old town setting of Pamplona. While the majority of the tourist respondents claimed not to worry if the event was staged for them, they all claimed that its physical location was significant to their experience. A clear distinction is made here, by the tourists, residents, and local government, between the old town and suburban Pamplona: "The Sanfermines has a kind of natural boundary in terms of where it is celebrated which keeps almost exactly to the limits of the old town" (Azpilicueta and Domench, 1994, p. 51).
In this way, the "naturalness" of the old town, with its narrow streets, open squares, and old buildings, is transferred to the Sanfermines: both are integral parts of tradition, of Pamplona's physical, social, and cultural heritage. In contrast, the suburbs have what amounts to their own festival, comprised largely of music and processions. In addition, the suburban areas surrounding the old town also act as a type of "service area," with restaurants and bars taking over the streets.

As a celebration of Pamplona's heritage, therefore, the Sanfermines is, almost literally, written into this landscape. As a result, all those who participate in the fiesta can feel an attachment to it, even if their social or familial connection is weak or nonexistent. In continuing to situate the fiesta in the old town, the local government is thus effectively appropriating the architectural spectacle as an iconic connection to the culture and history of the Sanfermines and, through the Sanfermines, to the culture and history of Pamplona and Navarre themselves.

\section{Internalizing the Contradictions of Commodification and Regulation}

In pursuing the goal of social regulation, Bakhtin's (1984) construct of the carnivalesque has little place for overt commodification, particularly when it is focused on attracting tourists. However, it is apparent that much of the commodification of the Sanfermines is, in policy terms at least, an adjunct rather than a challenge to regulation. To a large extent, this is acceptedinternalized-by the residents. While recognizing the commercialization and commodification of the fiesta, they equally view its impacts on Pamplona as marginal and, largely, temporary. As Table 5 illustrates, the mean responses of residents indicated that only employment opportunities were perceived to improve (and then only slightly) as a result of tourism during the fiesta in Pamplona. Alternatively, morality, crime, fights, vandalism, drugs, alcoholism, prostitution, traffic conditions, and pollution were all perceived by the residents to worsen slightly during the fiesta. In overall terms, however, their standard of living and quality of life remain largely unaffected by the Sanfermines. 
Table 5

Overall Residents' Perceptions Towards the Social Impacts of Tourism in Pamplona During the San Fermin Fiesta

\begin{tabular}{lll}
\hline Impact Variables & Mean & SD \\
\hline Standard of living & 3.044 & 0.830 \\
Employment opportunities & 3.529 & 0.882 \\
Personal income & 3.235 & 0.788 \\
Quality of life & 2.853 & 0.713 \\
Municipal tax & 2.868 & 0.662 \\
Courtesy \& hospitality towards tourists & 3.265 & 0.994 \\
Honesty in commercial exchange & 2.706 & 0.924 \\
Mutual trust among people & 2.662 & 0.851 \\
Morality & 2.485 & 0.849 \\
Sexual permissiveness & 2.882 & 1.131 \\
Individual crime & 2.441 & 0.735 \\
Organized crime & 2.882 & 0.471 \\
Fights & 2.147 & 0.895 \\
Vandalism & 2.015 & 0.849 \\
Drugs & 2.162 & 0.851 \\
Alcoholism & 1.897 & 0.987 \\
Prostitution & 2.515 & 0.849 \\
Traffic condition & 1.868 & 0.726 \\
Pollution & 2.309 & 0.743 \\
Grand mean & 2.619 & \\
\hline
\end{tabular}

Scale: 1 = significantly decline, $2=$ decline, $3=$ no difference, 4 = improve, 5 = significantly improve.

The degree to which the commodification of the fiesta is internalized is partially a function of age. As Table 6 shows, the younger residents are generally more able than the older residents to accommodate the impacts of the fiesta. In particular, quality of life is much less an issue for the younger people, while the behavior of the tourists is less at odds with the expectations of the young than it is with the older people. In overall terms, however, few residents have trouble internalizing the commodification of the fiesta, with nearly half feeling that the presence of tourists impacts little on their experience and enjoyment.

In contrast to the relative ease with which the residents appear to internalize the impacts of the tourists, many of the tourists have problems with the local regulatory framework. Indeed, while being in awe of the Spanish ability to party, some tourists find aspects of the fiesta, such as the daily bullfights, distressing or distasteful. As Stavrou (1999) suggests, in a telling passage from his description of the fiesta, many tourists desire a "sanitized" version of the festival, with some aspects of its heritage-specifically the bullfights-removed from the spectacle.
Table 6

Perceptual Differences Between Residents in Different Age Categories

\begin{tabular}{lcc}
\hline & \multicolumn{2}{c}{ Means } \\
\cline { 2 - 3 } Impact Variables & $18-30$ & 41 \& Over \\
\hline Standard of living & 3.194 & 3.000 \\
Employment opportunities & 3.556 & 3.500 \\
Personal income & 3.222 & 3.000 \\
Quality of life & 3.000 & 2.600 \\
Municipal tax & 2.861 & 2.700 \\
Courtesy \& hospitality towards tourists & 3.167 & 3.600 \\
Honesty in commercial exchange & 2.583 & 2.700 \\
Mutual trust among people & 2.611 & 2.900 \\
Morality & 2.444 & 2.400 \\
Sexual permissiveness & 0.056 & 0.200 \\
Individual crime & 2.306 & 2.600 \\
Organized crime & 2.917 & 2.700 \\
Fights & 2.083 & 2.100 \\
Vandalism & 1.944 & 2.000 \\
Drugs & 2.194 & 2.200 \\
Alcoholism & 1.944 & 1.700 \\
Prostitution & 2.500 & 2.500 \\
Traffic condition & 1.750 & 2.200 \\
Pollution & 2.222 & 2.200 \\
Grand mean & 2.608 & 2.568 \\
\hline
\end{tabular}

Scale: 1 = significantly decline, $2=$ decline, $3=$ no difference, 4 = improve, 5 = significantly improve.

In promoting the identity of the fiesta as commodified spectacle, Stavrou argues that the sensibilities of the visitors should be set against those of the resident community: "its okay to dislike aspects of their culture because there are plenty of things about our culture that they dislike" (Stavrou, 1999 , p. 2).

There is no evidence that such sensibilities are likely to lead to any dilution of this aspect of the fiesta. Indeed, as we argue, the commodification is an integral element of the regulatory frame, certainly in seeking to connect Pamplona with the world beyond and thus to invert its conventional chauvinist insularity. To dilute the spectacle of the bull fights, or to prevent drunken people from participating in, and occasionally being killed by, the encierros, would thus be less the internalization of commodification than it would be the complete denial of the social regulatory framework. In contrast to many other festivals, therefore, the problems of internalizing the contradictions between commodification and regulation lie less with the residents than with the tourists. 


\section{Discussion: Consumption of the Everyday}

What is immediately apparent about the San Fermin fiesta is the superficial invisibility of the distinction between resident and tourist: the collective memory is articulated as a street party to which all are invited. Rather than reflecting a cultural heritage, whether shared or displayed, the collective memory has been, in Goldman and Papson's (1994) terms, "rerouted." Reflecting MacCannell's (1992) arguments, this new route is - with the exception of some residents-almost entirely dismissive of the sociocultural context of the fiesta, and of the impact it has on those living in Pamplona. Instead, it places Pamplona on a global "party map," famous for its drinking and bull-running and legitimized more by its literary associations with Hemmingway than with its patron, Saint Fermin (cf. Stavrou, 1999).

This view is actively appropriated by the local authorities (Ayuntamiento de Pamplona, 1999; Gobierno de Navarre, 1997), who promote the inclusivity of the fiesta: "nobody remains a stranger for long." In contrast to Hinch and Delamere's (1993) findings about the need for local governments to inculcate tourists into the meaning of the festival, those associated with the Sanfermines feel no such compunction. Indeed, in comparison with the official presentation of other international festivals such as the New Orleans Mardi Gras (City of New Orleans, 1999), the Pamplona authorities play down the historical meaning of the San Fermin fiesta. Rather, there is an overt attempt to locate the cultural context for the fiesta in the contemporary characterization of the street party.

To a large extent the residents acquiesce in this, in reflecting that a failure by tourists to understand the religious significance of the fiesta does not lead to antipathy, but to acceptance, even welcome. However, while it might be tempting to locate this within a paradigm of staged authenticity (MacCannell, 1973), there is no evidence to suggest that there is any major or thorough-going "staging." Indeed, it can be argued that cultural production remains intact within the events organized by the Penas, while there is certainly evidence that the party atmosphere and carnival are consumed equally by the residents and the visitors.

It is thus tempting to ask whether the Sanfermines has any greater significance than being a good "get- together" characterized by participation, for some, in an extreme act of consumption-related both to the week of "nonstop" partying and to the bull-running. For MacCannell (1992, p. 231), it is the very act of abandoning (and being encouraged to abandon) self-control that represents the functional purpose of the carnival, for it is at this moment that people must inevitably accede to the continuation of social structure and control. This, argues Rojek (1995), is the effective "lie" of the carnivalesque: that the revelry that mimics dissention, and even anarchy, can only take place in the knowledge that it is legitimized and bounded by the everyday.

Rather than flouting the everyday, therefore, the carnival actually consumes it. The carnival becomes the everyday (MacCannell, 1992), thus denying the distinction that it has seemingly created. The production and performance of the Sanfermines, from the Chupizano to the Pobre de mi, serve to remind people that, while they may enjoy a relaxed behavioral license during the fiesta, the social structure of the everyday remains intact and functional. What shifts during the fiesta is people's understanding and experience of the spaces and time associated with the events. The streets over which the bulls run become a "survival zone," the piazzas a stage and dance floor, the fountain in the Plaza de la Constitucion a platform from which to dive into the crowd, and the suburban streets an alfresco eatery.

The spaces and time occupied by the San Fermin fiesta are, thus, avowedly liminal in character (Shields, 1992). Not only do they facilitate activities that would be considered deviant in other times and spaces, but they also ensure, through their connection to the everyday, that the "moral curtain" remains in place and intact in the longer term (even if it is, in Shields' terms, raised a little in the short term). The activities that take place in these liminal zones have many of the characteristics of the mimetic (Elias \& Dunning, 1986). This is particularly so in the case of the bull-running, where descriptions of participation (cf. Stavrou, 1999) use a rhetoric of danger, injury, machismo, and adrenaline-rush more usually associated with physical aggression and combat.

A common theme in describing these zones is that they are sites of release (Elias, 1978; MacCannell, 1992). Release in this sense does not imply freedom-as in release from structure or control—but 
licensed elision according to a predetermined structure of social relations (Lefebvre, 1991). Release is thus a highly constructed and constrained term, governed by the overarching heterotropia that is the fiesta or carnival itself (Foucault, 1975).

In constructing and promoting the heterotropia of the Sanfermines as a site of release, the people of Pamplona have been able to derive a "route" towards the acceptance of changing social and cultural values and expectations. The tourists are significant in this process, in providing "markers" along the way. It is clear from the questionnaire responses that the fiesta is widely perceived by residents to have changed over time. Yet this change is not seen to be the result of either internal or external influence. Neither is it viewed as undermining the continuing purpose and cultural significance of the fiesta. Rather, it has become embodied by the residents as a "natural" phenomenon-written into the very landscape that is the old town of Pamplona. The fiesta thus effectively assumes the benign role of a "marker" of social change, a reflection of wider structural influences.

This is played out by the residents in a number of ways. One of these, for example, is the intergenerational difference over the issue of sexual permissiveness. Both younger and older generations appear capable of recognizing the impacts of the wider changes in social and moral values. However, the older generation is able to blame the fiesta for "importing" greater permissiveness into Pamplona, while the younger generation has the space to deny this, while enjoying the greater "freedom" licensed by the fiesta.

Rather than being incidental to this negotiation of social values, the visitors are fundamental to its success as a social and political project. Without the visitors, the lifting of the "moral curtain" (Shields, 1992) could carry severe penalties, particularly in undermining confidence in the stability of the community. With visitors, especially in the numbers attracted to the Sanfermines, the apparent "immorality" of some residents is diffused or disguised. In Stavrou's (1999) terms, the "drunk Spaniard" both authenticates and legitimizes the activities and experiences of the visitors, just as the "drunk visitor" lends proportion to the activities of the residents. Equally, many of the residents suggest that they like to meet the visitors, while the local authorities put considerable efforts into maintaining the Sanfermines as a major tourist attraction.

More important, however, particularly in recognizing Bakhtin (1984), is the nature of the inversion of the carnivalesque. As MacCannell (1992, p. 230) suggests, some readings of the carnival implicitly suggest that, for example, mob violence is a simple transformation of ritual celebration. Moreover, this type of transformation is more likely to occur when the participants share community or political affiliation. Where the concentration of the resident community is heavily diluted, as in the Sanfermines, the inversion can be essentially playful and convivial (Hughes, 1999). This does not automatically lead to a lack of violence, but it reduces the potential for organized and violent challenges to the dominant authorities. It equally diffuses the bravura that may otherwise become associated with events such as the encierro.

Thus, the Sanfermines is characterized as both a global and a local celebration, in which people come together to party. The inversion is understood, contrary to MacCannell (1992), as a shift from the chauvinist community of everyday family lives to the egalitarian atomism of the carnival. While achieving the intended elision, the transitional project is thus very much associated with underwriting, rather than challenging, the existing social structure. As suggested by Bakhtin (1984), therefore, the carnivalesque-epitomized by the San Fermin fiesta-remains a significant device for maintaining community governance and social control.

Recognition of this suggests that there is a clear case for rejecting contemporary narratives that place festivals as sites for the interpretation of local cultures and rituals. Indeed, this article indicates clearly that the construct of interpretation is rejected by both residents and visitors: neither group is naive enough to believe that authenticity resides in representation, or even cultural (re)production. Rather, as MacCannell (1992) and Couldry (1998) have previously made clear, authenticity resides with the intensity of emotion experienced by the individual.

It is the framing and governance of this relationship that is the focus of the festival. In creating liminal zones, both spatially and temporally, communities have the ability to "route" the intensity and direction of people's emotions (Goldman \& Papson, 1994). This routing can take a variety of forms, but 
is characterized by Shields' (1992) metaphor of the raising and lowering (and even repositioning) of the "moral curtain." The ways in which this is achieved, the degree to which the curtain is lifted, the precise position in which it is lowered, all act as signals to the community, apprising them of the boundaries or frame within which civil society may operate. While the festival, as carnivalesque, may provide a space and time in which to "break out" of this frame, the cognition by all is that this is no more than a temporary elision from the everyday structures of governance and control.

\section{References}

Ayuntamiento de Pamplona. (1998). San Fermin 1998Programa. Pamplona: Author.

Ayuntamiento de Pamplona. (1999). The fiestas of San Fermin. www.pamplona.net/engl/tourism/sfermin.html [accessed October 29, 1999).

Azpilicueta, L., \& Domench, J. M. (1994). Sanfermines. Pamplona: Departamento de Industria, Comercio, Turismo y Trabajo, Gobierno de Navarra.

Bakhtin, M. (1984). Rabelais and his world (trans. H. Iswolsky). Bloomington: Indiana University Press.

Belisle, F. J., \& Hoy, D. R. (1980). The perceived impact of tourism by residents: A case study in Santa Marta, Colombia. Annals of Tourism Research, 7(1), 83-96.

Bompard, P. (2001, June 22). Sainted or tainted? The Times Higher Education Supplement, p. 17.

City of New Orleans. (1999). Mardigras. www.neworleans. com/mardi.html (accessed October 29, 1999).

CNN. (1997). Carnaval. http://cnn.com/TRAVEL/DESTINATIONS/9702/MO.carnaval/mainframe /intro.html (accessed October 29, 1999).

Couldry, N. (1998). The view from inside the "simulacrum": Visitors' tales from the set of Coronation Street. Leisure Studies, 17(2), 94-107.

Delamere, T. A. (1997). Development of scale items to measure the social impact of community festivals. Journal of Applied Recreation Research, 22(4), 293-315.

Elias, N. (1978). The civilising process. Volume 1: The history of manners. Oxford: Blackwell.

Elias, N., \& Dunning, E. (1986). Quest for excitement: Sport and leisure in the civilising process. Oxford: Blackwell.

Foucault, M. (1975). Discipline and punish. Harmondsworth: Penguin.

Getz, D. (1991). Festivals, special events and tourism. New York: Van Nostrand Reinhold.

Getz, D. (1994). Event tourism and the authenticity dilemma. In W. Theobald (Ed.), Global tourism-the next decade (pp. 313-329). Oxford: Butterworth-Heinemann.

Getz, D., \& Cheyne, J. (1997). Special event tourism motivations and behaviour. In C. Ryan (Ed.), The tourist experience (pp. 136-154). London: Cassell.

Gobierno de Navarre. (1997). Resultados Encuestas San
Fermin-Año 1997. Pamplona: Departamento de Industria, Commercio, Turismo y Trabajo, Gobierno de Navarre.

Gobierno de Navarre. (1998a). Anuario 98 de turismo en Navarre. Pamplona: Departamento de Industria, Commercio, Turismo y Trabajo, Gobierno de Navarre.

Gobierno de Navarre. (1998b). Navarre-Sanfermines. Pamplona: Departamento de Industria, Commercio, Turismo y Trabajo, Gobierno de Navarre.

Goldman, R., \& Papson, S. (1994). Advertising in the age of hypersignification. Theory, Culture and Society, 11(3), 23-53.

Hemmingway, E. (1926/1995). The sun also rises. Basingstoke: Macmillan.

Hinch, T. D., \& Delamere, T. A. (1993). Native festivals as tourist attractions: A community challenge. Journal of Applied Recreation Research, 18(2), 131-142.

Hughes, G. (1999) Urban revitalization: The use of festive time strategies. Leisure Studies, 18(2), 119-135.

Jafari, J., Pizam, A., \& Przeclawski, K. (1990). A sociocultural study of tourism as a factor of change. Annals of Tourism Research, 17(3), 469-472.

King, B., Pizam, A., \& Milman, A. (1993). Social impacts of tourism: Host perceptions. Annals of Tourism Research, 20(4), 650-665.

Lefebvre, H. (1991). The production of space. Oxford: Blackwell.

MacCannell, D. (1973). Staged authenticity: On arrangements of social space in tourist settings. American Journal of Sociology, 79(3), 589-603.

MacCannell, D. (1992). Empty meeting grounds. London: Routledge.

Mauss, M. (1990). The gift. The form and reason for exchange in archaic societies (trans. W. Halls). London: Routledge.

Mennell, S. (1989). Norbert Elias: An introduction. Oxford: Blackwell.

Nogués Pedregal, A. M. (1996). Tourism and self-consciousness in a south Spanish coastal community. In J. Boissevain (Ed.), Coping with tourists. Oxford: Berghahn Books.

Philips, D. (1998). Carnival and control: The commodification of the carnivalesque at Disneyland. In N. Ravenscroft, D. Philips, \& M. Bennett (Eds.), Tourism and visitor attractions: Leisure, culture and commerce (pp. 75-82). Publication No. 61. Eastbourne: Leisure Studies Association.

Ravenscroft, N. (1999). Editorial: The created environment of heritage as leisure. International Journal of Heritage Studies, 5(2), 68-74.

Rojek, C. (1993). Ways of escape. Basingstoke: Macmillan. Rojek, C. (1995). Decentring leisure. London: Sage.

Sheldon, P. J., \& Var, T. (1984). Resident attitudes to tourism in North Wales. Tourism Management, 5, 40-47.

Shields, R. (1990). The system of pleasure. Theory, Culture and Society, 7(1), 39-72.

Shields, R. (1991). Places on the margin. London: Routledge. Shields, R. (1992). Spaces for the subject of consumption. In R. Shields (Ed.), Lifestyle shopping: The subject of 
consumption (pp. 1-21). London: Routledge.

Stavrou, S. (1999). Running with the bulls in Pamplona, Spain. http://members.aol.com/pfpubco/runbull.htm (accessed October 29, 1999).
The Scarlet Macaw. (1999). Adventures in travel: Sanfermines 2000; the Millennium run. http:// thescarletmacaw.com/encierro.htm (accessed November 5, 1999). 